\title{
LA UNION EUROPEA Y LA OTAN EN EL MARCO DE LA NUEVA ESTRATEGIA GLOBAL DE LA UNIÓN EUROPEA
}

\author{
Javier García ${ }^{1}$ \\ UNISCI / IE University
}

\section{Resumen}

El artículo analiza la relación entre la Unión Europea y la OTAN en cuestiones de defensa, según se ha reflejado en las estrategias de seguridad de la Unión Europea, con particular atención a la Estrategia Global de la Unión Europea presentada en 2016. Se estudia la Estrategia de Seguridad Europea de 2003, el Informe de Implementación de 2008, y las nuevas aproximaciones al contexto internacional y a la seguridad europea que se reflejan en la Estrategia Global. Se analiza también el papel de la OTAN, así como la evolución de la política de seguridad de los Estados Unidos hacia Europa durante la Administración Obama. Finalmente se discute el posible futuro de la Política Común de Seguridad y Defensa de la UE (PCSD) después del Bréxit, así como las consecuencias para su relación con la OTAN.

Palabras Clave: Estrategia Global de la Unión Europea, OTAN, Seguridad Europea, Defensa Europea, PCSD, Estrategia de Seguridad, Unión Europea

\section{Title in English: The European Union and NATO in the new Global Strategy of the European Union}

\begin{abstract}
:
The article analyzes the relationship between the European Union and NATO on defense issues, as reflected in the different security strategies of the European Union, with particular attention to the 2016 EU's Global Strategy. The paper focuses on the 2003 European Security Strategy, the 2008 Implementation Report, and the new approaches to both the international environment and the European security, that are developed in the Global Strategy. The evolution of NATO policy is also discussed, as well as the changes of the United States security and defence policy towards Europe during the Obama administration. Finally, the article discusses the future of the Common Security and Defense Policy of the EU (CSDP) after Brexit, and the consequences for the EU-NATO relationship.
\end{abstract}

Keywords: European Union Global Strategy, NATO, European Security, European Defence, CSDP, Security Strategy, European Union

Copyright (C) UNISCI, 2016.

Las opiniones expresadas en estos artículos son propias de sus autores, y no reflejan necesariamente la opinión de UNISCI. The views expressed in these articles are those of the authors, and do not necessarily reflect the views of UNISCI

\footnotetext{
${ }^{1}$ El Dr. Javier Ignacio García González es profesor de relaciones internacionales, globalización y ciencias políticas en "IE School of Human Sciences and Technology" es investigador senior de UNISCI

Dirección: Escuela de Comunicación, IE University, Campus de Santa Cruz la Real, C/ Cardenal Zúñiga 12, 40003 Segovia, España

E-mail: javier.garcia@ie.edu

DOI: http://dx.doi.org/10.5209/RUNI.53794
} 


\section{1.- Introducción}

El 28 de junio de 2016, durante la reunión del Consejo Europeo en Bruselas, la Alta Representante para Asuntos Exteriores y Política de Seguridad de la Unión Europea (UE), Federica Mogherini, presentaba oficialmente a los jefes de estado y gobierno de la Unión el texto de la nueva "Estrategia Global de la UE sobre Política Exterior y de Seguridad" (EG).

La ocasión debía de ser un momento importante. Se trataba de un documento largamente esperado, resultado de un completo proceso de estudio y reflexión lanzado en la cumbre de diciembre de 2013 y que contó con un encargo específico en el Consejo de junio de 2015, al que se daba cumplimiento según lo previsto. Es el tercer texto de este tipo tras la primera Estrategia de la Unión Europea del año 2003 -con Javier Solana como Alto Represente- y la actualización que se presentó en 2008, es decir, un texto de referencia para unos años de cambio profundo en la situación político-estratégica a nivel regional y global.

La Europa y el mundo que existían en los años 2003/2008 eran muy distintos de los que existen en 2016, y la Unión Europea precisaba desde hace tiempo de una estrategia que refleje la "visión" que se tiene del nuevo entorno internacional, ciertas "orientaciones" sobre el papel que se quiere desempeñar, así como una definición de las aspiraciones de la Unión en el contexto actual. El ámbito de la defensa es uno de los que ha sufrido transformaciones más importantes y el documento debía fijar la posición de la Unión en ese nuevo escenario; de forma particular, se debía plantear hacia dónde debe ir la relación entre la UE y la Organización del Tratado del Atlántico Norte (OTAN), alianza en la que ha descansado durante décadas la defensa del Viejo Continente y donde el papel de los Estados Unidos -y sus prioridades en política de seguridad- es fundamental. La evolución de esta relación, en los documentos estratégicos europeos y en la práctica entre ambas organizaciones, será el objeto central de este trabajo, con especial atención al análisis de los nuevos planteamientos propuestos en la EG.

Este análisis, no obstante, aparecerá fuertemente condicionado por el contexto inmediato en el que se presenta la Estrategia. La llegada del nuevo documento no podía producirse en un momento más complicado. En la reunión del Consejo, la Unión Europea estaba bajo los efectos del terremoto que supuso el resultado del referéndum sobre la salida del Reino Unido de la Unión apenas 5 días antes. El ya conocido como Brexit sacudía los cimientos de la organización y dejaba poco tiempo y espacio para tratar otros temas. Así, pese a su relevancia, la presentación del texto pasó casi completamente desapercibida. Las Conclusiones del Consejo apenas lo recogían con un único y lacónico párrafo que señala: "El Consejo Europeo se ha congratulado de la presentación, por la alta representante, de la Estrategia Global sobre política exterior y de seguridad de la Unión, y ha invitado a la Alta Representante, a la Comisión y al Consejo a que prosiga su labor"2. Tan solo eso, se tomaba nota del documento, se invita a seguir trabajando y a otro tema.

Por si no estaba claro, la escasa atención e interés con la que se recibía el documento también era perceptible unos días después en el informe que el Presidente del Consejo, Donald Tusk, presentaba al Parlamento Europeo sobre los resultados de la cumbre. En una intervención donde sobre todo se hablaba del Brexit, la crisis migratoria o las relaciones con Turquía, simplemente se señalaba sobre este asunto que "dimos la bienvenida a la presentación por la Alta Representante de una nueva estrategia global para orientar la política exterior y de seguridad de la Unión" ${ }^{3}$. No más referencias al tema.

\footnotetext{
${ }^{2}$ Consejo Europeo ,28 de junio de 2016, Conclusiones, Bruselas, EUCO 26/16, par. 20.

${ }^{3}$ European Council. The President, Report by President Donald Tusk to the European Parliament on the European Council of 28 June and the informal meeting of 27 EU Leaders on 29 June 2016, Statements and
} 
Con un recibimiento así, se hace difícil valorar el impacto que puede tener el documento, y si su contenido llegará a implementarse o, como algunos señalan, puede estar condenada a la irrelevancia desde su nacimiento, como sucedió con la revisión de $2008^{4}$. ¿Da respuesta entonces la EG a los desafíos y necesidades que tiene que enfrentar la Unión Europea en los próximos años? ¿Hay diferencias en la EG respecto a cómo recogían los documentos estratégicos anteriores la relación entre la Unión Europea y la OTAN? ¿Se plantea algún cambio sustancial de la relación en el nuevo contexto?

Paradójicamente, la crisis generada por el referéndum está provocando un fuerte efecto de reacción precisamente en el ámbito de la Estrategia en el que nos centramos aquí, la defensa. Así, el Brexit ha servido de catalizador para que los principales países restantes de la Unión intenten poner en marcha una serie de iniciativas para reforzar la cooperación en materia de defensa, algo a lo que el Reino Unido tradicionalmente se había opuesto y llevaba lustros dificultando. Cuando se escribe este texto es muy pronto para aventurar la evolución de estas iniciativas, pero los movimientos iniciales ya permiten identificar nuevos objetivos y aspiraciones, que van en la línea de lo que se recoge en la EG.

En todo caso, en lo que respecta a la relación entre la Unión Europea y la OTAN, la Estrategia de la Unión es solo uno de los elementos a tener en cuenta y no debe ser analizada de forma aislada. Aunque resulta obvio señalarlo, la situación y evolución de la propia OTAN y el papel que ha jugado y quiere jugar en esa relación será determinante. De hecho, apenas 10 días después de la presentación de la Estrategia europea se celebró la cumbre de Varsovia de la OTAN, donde la firma de una declaración conjunta entre la Unión Europea y la OTAN fue uno de los temas destacados de la agenda. Titulares como "la OTAN y la Unión Europea acuerdan poner fin a su rivalidad" ${ }^{5}$, daban cuenta del espíritu del documento. El comienzo de la declaración es claro en su propósito: "Pensamos que ha llegado el momento de dar a la asociación estratégica OTAN-UE un nuevo impulso $y$ un nuevo contenido" 6 . Independientemente de que esto suponga un cambio significativo real de las relaciones entre ambas organizaciones o sea una más de las frecuentes declaraciones políticas con pocos efectos prácticos -lo analizaremos más adelante-, la declaración nos sitúa ante nuevas realidades. Un nuevo contexto al que tampoco será ajeno el compromiso que Estados Unidos la nueva administración resultante de las elecciones de 2016- quiera mantener con la OTAN como instrumento de la defensa europea, de la que hasta ahora ha sido su principal contribuyente militar.

Con esta situación, las siguientes páginas harán un análisis de la evolución de la relación entre la UE y la OTAN a partir de cómo se contemplaba en la primera estrategia que presentó la Unión en 2003, en sus adaptaciones y trabajos posteriores, hasta llegar a lo que recoge la nueva EG de 2016 y el contexto de seguridad y defensa en el que se ha presentado el documento. Se podrán así identificar las grandes líneas políticas y de acción en las que esta relación se ha movido, las distintas fuerzas que han ido afectando a la convivencia entre ambas organizaciones, y cómo todo ello ha influido en la EG y su eventual implementación.

Remarks 412/16, 05/07/2016, en http://www.consilium.europa.eu/en/press/press-releases/2016/07/06-tuskreport-european-parliament/

${ }^{4}$ Arteaga, Félix: “¿La Estrategia Global de la UE?... déjela ahí”, Blog Elcano, 29 de junio de 2016, en http://www.blog.rielcano.org/la-estrategia-global-de-la-ue-dejela-ahi/

5 Dempsey, Judy: "NATO and the EU Agree to End Their Rivalry", Carnegie Europe, July 8, 2016, en http://carnegieeurope.eu/strategiceurope/?fa $=64045$

${ }^{6}$ Joint Declaration by the President of the European Council, the President of the European Commission, nd the Secretary General of the North Atlantic Treaty Organizations, Brussels, 8 July, 2016, en http://europa.eu/rapid/press-release_STATEMENT-16-2459_en.htm 


\section{2.- La Unión Europea y la OTAN al comienzo del siglo XXI: la Estrategia europea de} 2003.

Hay que esperar hasta finales de la década de los 90 del siglo XX para que la Unión Europea se empiece a plantear la asunción de algún tipo de responsabilidades en cuestiones militares y de defensa. El monopolio sobre la seguridad europea que ejerció la OTAN durante la Guerra Fría, en absoluto se vio afectado por la existencia de una organización europea, la Unión Europea Occidental (UEO), que prácticamente sólo tuvo una actividad operativa simbólica ${ }^{7}$, aunque en su seno se desarrollara la idea de las "Misiones Petersberg", que con la firma del Tratado de Amsterdam en 1997, pasaron a formar parte del Tratado de la Unión Europea sin ninguna modificación, incorporándolas como parte de la Política Exterior y de Seguridad Común ${ }^{8}$.

La guerra de Kosovo fue fundamental para dar un impulso a la voluntad de dar a la Unión una dimensión de defensa, aunque se iniciará como el desarrollo de la voluntad "de poner en práctica una política de gestión de crisis exteriores"9. En otras palabras, se pone el foco en poder desarrollar intervenciones en conflictos externos de diverso tipo, pero sobre todo en escenarios pos-bélicos y de mantenimiento de la paz. La incapacidad europea en Kosovo, donde el peso de las operaciones militares lo llevó la OTAN, hizo reconocer lo inadecuado de los instrumentos militares de la Unión, y se puso en marcha el desarrollo de una Política Europea de Seguridad y Defensa (PESD) que tendrá como referencia de nacimiento "oficial" la cumbre franco-británica de Saint-Malo en diciembre de 1998.

Probablemente el aspecto más relevante de la citada cumbre sea que el Reino Unido, dando un importante giro a su tradicional rechazo a toda cooperación exclusivamente europea en temas de defensa, planteaba junto con Francia que la Unión "debe tener capacidad para actuar de forma autónoma, respaldada por fuerzas militares creíbles, por los medios para decidir su uso y la preparación para hacerlo, con el fin de dar respuesta a las crisis internacionales"10. Eso sí, de forma explícita se dejaba claro también el compromiso con la OTAN respecto a la defensa colectiva. Se abría de este modo en la UE una línea en que otros países como Alemania también compartían, como señalaba esos mismos días la declaración final de la cumbre franco-alemana: "nos debemos movilizar para la prevención y la gestión de crisis regionales (antigua Yugoslavia y Oriente Medio). Con este fin, buscaremos las vías que permitan a la UE disponer de las capacidades operacionales que le faltan, bien dotándole de medios europeos propios (a través de la UEO o de las fuerzas multinacionales europeas como el Eurocuerpo) o con medios de la OTAN en aplicación de los acuerdos firmados en el Consejo Atlántico de Berlín" "11. Un nuevo contexto se estaba dibujando para la cooperación

\footnotetext{
${ }^{7}$ Ver García González, Javier Ignacio: “Crisis y Gestión Militar de la Crisis en la Unión Europea: El Camino hasta la Actualización de la Estrategia Europea de Seguridad”, en UNISCI Discussion Papers, no 19 (2009), pp. 243-246. Las operaciones militares más destacadas de la UEO fueron dos operaciones navales, en el Golfo en 1988-90 y en la antigua Yugoslavia en 1992, una fluvial en el Danubio en 1993 y algunos contingentes de policía, vigilancia y desminado en Mostar, Albania, Croacia y Kosovo. Detalles de estas operaciones se pueden consultar en www.weu.int.

${ }^{8}$ Versión Consolidada del Tratado de la Unión Europea (97/C 340/02), Diario Oficial de las Comunidades Europeas, 10.11.97, Artículo 17, apartados 1 y 2. El apartado 17.2 señala: "Las misiones a las que se refiere el presente artículo incluirán misiones humanitarias y de rescate, misiones de mantenimiento de la paz y misiones en las que intervengan fuerzas de combate para la gestión de crisis, incluidas las misiones de restablecimiento de la paz."

9 Solana, Javier (2004): "Prólogo", en Gnesotto, Nicole (ed.): Política de Defensa de la Unión Europea. Los cinco primeros años (1999-2004), París, Instituto de Estudios de Seguridad de la Unión Europea, p. 5.

${ }^{10}$ Joint Declaration, British-French summit St-Mao, 3,4 December 1998. par. 2, en http://www.consilium.europa.eu/uedocs/cmsupload/French-British\%20Summit\%20Declaration,\%20SaintMalo,\%201998\%20-\%20EN.pdf

11 "Franco-German summit. Postdam, 1 December 1998", en Rutten, Maartje (comp.) (2001): From St-Malo to Nice. European defence: core documents, Chaillot Papers 47, May 2001, p. 4.
} 
europea en materia de defensa, que se hacía sin menoscabo de la OTAN como principal elemento de la defensa colectiva.

La institucionalización de la Política Europea de Seguridad y Defensa se produciría a partir del Consejo Europeo de Helsinki de 1999, sentando las bases para la creación del Comité Político y de Seguridad, el Comité Militar y el Estado Mayor de la Unión Europea ${ }^{12}$. A partir de aquí, la Unión puso en marcha en los años siguientes una serie de procedimientos, mecanismos y capacidades militares y civiles -muy modestos y muchos de ellos solo sobre el papel-, pero que le permitieron lanzar en 2003 su primera operación, la operación Artemis, a pesar de fuertes reticencias estadounidenses. Kofi Annan había solicitado el despliegue de una fuerza multinacional temporal al área hasta que la misión de la ONU, la MONUC, bastante debilitada, pudiera a su vez reforzarse y desplegarse. La Unión Europea entraba así en el campo de las operaciones de lo que denomina "gestión de crisis"13, es decir, intervenciones en el exterior, con un componente civil (misiones) o militar (operaciones) generalmente apoyando procesos de mantenimiento o consolidación de la paz tras el cese de la lucha armada en un conflicto.

En este contexto de incipiente actividad de la Unión Europea en el ámbito de la seguridad y la defensa, ese mismo año 2003 se publicará la primera Estrategia Europea de Seguridad (EES-2003), titulada "Una Europa Segura en un Mundo Mejor"14. Como terminaba la introducción del documento "Europa tiene que estar dispuesta a asumir su responsabilidad en el mantenimiento de la seguridad mundial y la construcción de un mundo mejor" 15 . Quedaba por ver si esto iba a ser así, de que manera se haría y el papel que según la Estrategia iba a jugar la relación con la OTAN en los nuevos escenarios que se describen.

La EES-2003 es un documento que parte de una visión optimista del entorno de seguridad europeo; "Europea no ha sido nunca tan próspera, tan segura ni tan libre" señala en su primera frase. Una situación que por supuesto se atribuye a la creación, desarrollo y ampliación de la Unión Europea, pero en la que reconoce un papel "esencial" a Estados Unidos, principalmente a través de la OTAN, organización a la que a partir de aquí se referirá en pocas ocasiones. La Alianza Atlántica no ocupará así un espacio significativo en la primera estrategia de la Unión Europea. Sí se recogerá su participación relevante en el último conflicto armado sufrido en Europa hasta esa época (el conflicto de los Balcanes), pero al lado de la propia Unión, Rusia, los Estados Unidos y otros "interlocutores internacionales"16. La situación en Irak, que tanta tensión estaba generando entre los países europeos y en la relación con Estados Unidos no se cita ni una sola vez.

Su principal relevancia, por lo que se dice y se enfatiza en el texto, estará por tanto en su condición de manifestación del vinculo transatlántico, como instrumento de la relación entre Europa y Estados Unidos, en un momento en que la superioridad militar norteamericana, según la estrategia, no es suficiente para "hacer frente en solitario a los complejos problemas del mundo de hoy"17. En esta línea, la EES-2003 plantea "Un orden internacional basado en un multilateralismo eficaz" -es el título de uno de sus apartados-, en el que la OTAN no es

\footnotetext{
${ }^{12}$ Freire, María Raquel. y Galantino, María Grazia.: "Introduction: The Role of the EU in International Peace and Security", en Freire, María Raquel y Galantino, María Grazia (2015): Managing Crisis, Making Peace. Towards a Strategic EU Vision for Security and Defense, Basingstok, Palgrave, p. 4.

${ }^{13}$ Ver Tardy, Thierry (2015): CSDP in Action-What Contribution to International Security, Chaillot Papers $\mathrm{n}^{\circ}$ 134, ISSEU, May 2015, pp. 9-12.

${ }^{14}$ Una Europa segura en un mundo mejor. Estrategia Europea de Seguridad, Bruselas, 12 de diciembre de 2003, en http://www.consilium.europa.eu/uedocs/cmsupload/031208essiies.pdf

15 Ibid, p. 1.

${ }^{16}$ Ibid, p. 8.

${ }^{17}$ Ibid. p. 1.
} 
más que una de los distintos actores con los que interactúa (ONU, OMC, Rusia, OSCE, Consejo de Europa, ASEAN, Mercosur o la Unión Africana), identificado fundamentalmente como elemento central de las relaciones transatlánticas, como señalamos.

En este contexto, donde una eventual agresión de gran escala a alguno de los Estados Miembros de la Unión es calificada en la Estrategia como "improbable"18, no se reserva un especial papel a la OTAN al tratar las amenazas a la seguridad de la UE que se identifican: el terrorismo, la proliferación de armas de destrucción masiva, los distintos efectos de los conflictos regionales, la descomposición de Estados o la delincuencia organizada. Se habla de estos fenómenos como "menos visibles y menos previsibles" que las amenazas clásicas, pero no hay referencias expresas a una posible colaboración UE-OTAN que sí se hará en otros momentos.

Cuando se habla de las capacidades operativas de la UE, que se ve necesario potenciar con más recursos y un uso más eficaz, sí se menciona la Alianza. Una forma de reforzarlas a corto plazo serán los "dispositivos permanentes UE-OTAN, en particular los acuerdos Berlín Plus"19, que se firmaron entre ambas organizaciones en ese mismo 2003. Estos acuerdos permitirían a la UE hacer uso de medios y capacidades de la OTAN de las que carecía para operaciones de gestión de crisis dirigidas por la Unión ${ }^{20}$. De hecho, la primera operación militar dirigida por la UE, la Operación Concordia, lanzada en la antigua Republica Yugoslava de Macedonia el 31 de marzo de 2003, se llevó a cabo bajo estos acuerdos de cooperación. También se utilizaron en la operación EUFOR Althea en Bosnia y Herzegovina en 2004, sin tener más recorrido posterior.

Berlín Plus suponía poner al alcance de la UE medios de los que no disponía, pero, a su vez, implicaba una dependencia de la OTAN y una limitación en su autonomía y flexibilidad para preparar misiones de "gestión de crisis" propias. Esto podía, a juicio de algunos, frenar el incipiente desarrollo de la PESD, y Francia, todavía fuera de la estructura miliar de la Alianza, era reticente a aumentar la agenda de cooperación entre ambas organizaciones $^{21}$. Por otra parte, la visión de la UE en los distintos escenarios no necesariamente tenía que coincidir con la de OTAN como organización, o con la de algunos de sus miembros como Turquía, que tenían sus propios intereses y prioridades nacionales. La entrada de Chipre en la Unión en 2004 no facilitó el acercamiento entre las organizaciones e impuso una restricción a las relaciones formales UE-OTAN ${ }^{22}$. A estos problemas, no se hacía referencia en la Estrategia, lógicamente, como tampoco se ponía en cuestión en ninguna parte el papel prioritario de la OTAN en la defensa colectiva de los miembros.

\section{3.- EI Informe de actualización de la Estrategia en 2008 y sus secuelas.}

A finales de 2007, el entonces Secretario General/Alto Representante (SG/HR), Javier Solana, recibió el mandato del Consejo Europeo para analizar la ejecución de la Estrategia de 2003 -cuya redacción original también dirigió-, mejorar su puesta en práctica y proponer elementos para complementarla ${ }^{23}$. El resultado llegó un año después bajo el título Informe sobre la aplicación de la Estrategia Europea de Seguridad -Ofrecer seguridad en un mundo en

\footnotetext{
${ }^{18}$ Ibid, p. 3

${ }^{19}$ Ibid. p. 12

${ }^{20}$ European Union. External Action: About CSPD-The Berlin Plus Agreement, en http://eeas.europa.eu/csdp/about-csdp/berlin/

${ }^{21}$ Drent, Margriet (2015): "EU-NATO Relations in Crisis Management Operations: The Practice of Informality", en Freire, María Raquel y Galantino, María Grazia, op. cit. p. 96.

${ }^{22}$ Ibid, p. 92

${ }^{23}$ Conclusiones de la Presidencia. Consejo Europeo de Bruselas, 14 de diciembre de 2007, 166616/07, par. 90, en http://data.consilium.europa.eu/doc/document/ST-16616-2007-INIT/en/pdf
} 
evolución ${ }^{24}$-, de 11 de diciembre de 2008, una especie de "suplemento" de la EES-2003, mucho menos ambicioso de lo que Francia habría pretendido como resultado de su presidencia de turno en el segundo semestre de ese año ${ }^{25}$, que no era otra cosa que una nueva EES, algo que no contaba con el apoyo de Alemania o el Reino Unido ${ }^{26}$.

Tampoco entonces era el momento propicio para alcanzar los consensos necesarios para una nueva Estrategia de Seguridad. La gravedad de la crisis generada por la caída de Lehman Brothers, la guerra en Georgia, las expectativas de cambio político que había en Estados Unidos -que estaba en año electoral-, presentaban un contexto convulso poco apropiado para este tipo de documentos. Especialmente relevante eran las muestras de deterioro de la relación con Rusia, que ya en diciembre de 2007 había "suspendido" su implementación del Tratado de Fuerzas Convencionales en Europa (FCE), el que muchos consideran "la piedra angular de la seguridad europea"27. Únicamente mantuvo su asistencia al Grupo Consultivo Conjunto. Sería en marzo de 2015 cuando Rusia anuncio que ponía punto final a todas sus acciones en el FCE, lo anunciado en 2007, de forma completa, abandonando también este órgano.

Así, el Informe de 2008 no aportaba muchas novedades y se puede considerar esencialmente continuista con la EES-2003. Además de destacar los logros de la Unión en temas de seguridad desde la publicación de la primera estrategia, se ponen al día los acontecimientos relevantes, se mantiene la visión general, se confirman los retos y amenazas que enfrenta la Unión y se añaden al listado los ámbitos de la ciberseguridad, la seguridad energética y el cambio climático. Seguirá apareciendo la referencia a lo esencial que es tener estructuras de mando y capacidades adecuadas, pero sin mostrar un nivel de ambición o objetivos específicos que supusieran un salto hacia adelante para la Unión. Se reconoce el respeto a "la autonomía decisoria de cada organización", así como a la necesidad de reforzar la asociación estratégica y la cooperación entre la UE y la OTAN -en particular en la gestión de crisis $^{28}$-, lo que era una forma implícita de reconocer que el funcionamiento de las relaciones entre ambas organizaciones seguía sin ser fluido, especialmente al nivel político.

Antes del Informe, sólo desde 2007 ambas organizaciones empezaron a reconocer las dificultades que su falta de cooperación provocaba ${ }^{29}$. Se pone de manifiesto con alguno de los mismos escenarios a los que el documento se refiere, como es el caso de Somalia y la lucha contra la piratería, donde la UE y la OTAN habían desplegado operaciones distintas (Atalanta y Ocean Shield respectivamente) con similares responsabilidades, pero con cooperación e intercambio de información bastante limitada.

El Informe, en suma, introduce pocos elementos novedosos destacables, líneas de acción política distintas, o nuevos instrumentos de acción, ni de naturaleza civil, ni militares. No refleja cambios significativos en la relación de la UE con la OTAN, que en los años

\footnotetext{
${ }^{24}$ Informe sobre la aplicación de la Estrategia Europea de Seguridad-Ofrecer seguridad en un mundo en evolución-, documento 17104/8, Bruselas 11 de diciembre de 2008, en http://www.consilium.europa.eu/uedocs/cms data/docs/pressdata/ES/reports/104637.pdf

${ }_{25}$ Presidence Français de la Union Européenne (2008): Un Europe qui agit pour repondre aux defis d'aujourd'hui, Programme de Travail, 1er juillet-31 décembre 2008.Ver también Ministère de la Defense/ Presidence Français de la Union Européenne (2008): Objectives of the French Presidency of the European Union Council in terms of security and defense.

${ }^{26}$ Missiroli, Antonio (ed.) (2015): Towards an EU Global Strategy. Background, process, references, EU Institute for Security Studies, Paris, 2015, p. 39.

${ }^{27}$ Ver The Conventional Armed Forces in Europe (CFE) Treaty and Adapted CFE Treaty at a Glance, (August 2012), en www.armscontrol.org/factsheet/CFE

${ }^{28}$ Informe sobre la aplicación de la Estrategia Europea de Seguridad..., op. cit. p. 2.

${ }^{29}$ Drent, Margriet (2015), op. cit. p. 92.
} 
previos se habían desarrollado "lenta y cautelosamente"30 en cuanto al diálogo institucional. El no reconocimiento de Chipre (miembro de la Unión Europea) por Turquía (miembro de la OTAN) suponía un obstáculo importante para avanzar en los mecanismos de cooperación, que aparecían bloqueados $^{31}$. La vuelta de Francia a todos los organismos de la estructura militar de la OTAN en 2009 parecía que podría atenuar las dificultades de colaboración entre la UE y la OTAN, recibiendo un nuevo impulso ${ }^{32}$, pero los problemas con el tema de Chipre y la posición de Turquía persistían.

Como señala Pawlak ${ }^{33}$, las expectativas creadas cuando se anunció en 2007 la revisión de la estrategia original, se vieron completamente frustradas con las limitaciones del Informe de 2008. A partir de aquí, la concentración de los esfuerzos en la implementación del Tratado de Lisboa, relegaron toda discusión sobre una nueva estrategia, que pasó a ser un tema a largo plazo. El nombramiento de Catherine Ashton como Alta Representante de la Unión para Asuntos Exteriores y Política de Seguridad, fue también clave; "Ashton no compartía la opinión de que la UE necesitara una nueva estrategia de seguridad" 34 (de tipo general). Por el contrario, durante sus años en el puesto favoreció una línea completamente distinta, dando prioridad a la elaboración de estrategias de tipo regional (Sahel, Cuerno de África, Vecindad, etc.) o sobre ámbitos específicos (Comprenhensive Approach, Ciberseguridad, Seguridad Marítima, etc).

En cuanto a la relación Unión Europea-OTAN los años siguientes al Informe de 2008, Drent los ha definido dentro de una fase de "tensión o frágil normalización a través de las relaciones informales" 35 . Si bien las relaciones formales entre ambas organizaciones seguían sin avanzar, se mantenían algunas relaciones políticas informales y cierta cooperación operacional (también informal) en el ámbito militar, en los escenarios en los que ambas estaban presentes, la antigua Yugoslavia, Afganistán, Sudán o Somalia.

Desde Saint-Malo en 1998, pasando por la EES-2003, y como ocurrirá después del Informe de 2008, las aspiraciones o la ambición de la UE en el ámbito de seguridad y defensa europea no han cuestionado el papel prioritario de la OTAN en la defensa colectiva, ni la importante función que representa a la hora de mantener el vínculo transatlántico con los Estados Unidos. La inclusión de la Cláusula de Asistencia Mutua (art. 42.7) en el Tratado de Lisboa (TUE), o la Cláusula de Solidaridad (art. 222 del Tratado de Funcionamiento de la UE) no cambiaba la situación al mantener explícitamente que la OTAN "seguirá siendo, para los Estados miembros que son parte de la misma, el fundamento de su defensa colectiva y el organismo de ejecución de esta" ${ }^{36}$. La vía de la Cooperación Estructurada Permanente ${ }^{37}$, prevista en el TUE para permitir avanzar en determinados temas a un grupo limitado de países miembros -no necesariamente todos-, era también un camino abierto para la cooperación en defensa (compatible con la OTAN) ${ }^{38}$, pero no explorado todavía.

\footnotetext{
${ }^{30}$ Ver al respecto Duke, Simon: "The Future of EU- NATO Relations”, European Integration, Vol. 30, No 1, March 2008, p. 33

${ }^{31}$ Drent, Margriet (2015), op. cit. p. 96.

${ }^{32}$ Duke, Simon, op. cit. p. 40.

${ }^{33}$ Pawlak, Patric: "A Global Strategy on foreign and security policy for the EU”, Briefing, European

Parlamentary Research Service, EPRS, April 2016, p. 2.

${ }^{34}$ Ibid.

${ }^{35}$ Drent, Margriet (2015), op. cit. p. 98.

${ }^{36}$ Art 42.7 Tratado de la Unión Europea.

${ }^{37}$ Art 42.6, Tratado de la Unión Europea.

${ }^{38}$ Vease, Aldecoa, Francisco: "Una política de defensa europea compatible con la Alianza Atlántica", en VV. AA. (2015): UE-EEUU: Una relación indispensable para la paz y la estabilidad mundiales, Cuadernos de Estrategia, ${ }^{\circ} .177$, IEES/USP-CEU.
} 
De este modo, la actividad de la Unión Europea se ha circunscrito esencialmente al ámbito de la denominada "gestión de crisis" 39 entendida en un sentido claramente reducido, dentro de la soft security a la que nos referimos más arriba, lanzando desde 2003 más de una treintena de operaciones (militares) y misiones (civiles) prácticamente testimoniales y con funciones diversas. Es en este campo de los instrumentos civiles donde, por su propia naturaleza, la UE sí puede movilizar recursos de tipo policial, jurídico, administrativo, asistencia humanitaria, asistencia política, desarrollo, etc. con mayor flexibilidad que una organización fundamentalmente militar como OTAN ${ }^{40}$. Los tipos de tareas que se han asumido se han centrado principalmente en los ámbitos de la reconstrucción, la consolidación de la paz y la estabilización post-conflicto, el entrenamiento de fuerzas, la reforma del sector de la seguridad, la supervisión de acuerdos de paz o la lucha contra la piratería ${ }^{41}$.

En su conjunto se han tratado de operaciones y misiones importantes por su carácter simbólico, pero con ambiciones muy contenidas. Si bien constituyen un éxito con respecto a la inactividad de épocas pasadas, también han reflejado claramente las limitaciones en las capacidades militares de la Unión Europea. Incluso cuando la Unión ha desarrollado instrumentos que podrían ser adecuados para tener una mayor operatividad, como es el caso de los Battlegroups ${ }^{42}$, la falta de voluntad política para usarlos y financiarlos les ha vuelto inoperantes.

\section{4.- El otro lado de la relación: La OTAN y el vínculo transatlántico con Estados Unidos}

Como hemos visto, el desarrollo de la UE en el ámbito de la seguridad y la defensa desde el comienzo de siglo se ha realizado a la sombra de la OTAN. No se ha puesto en cuestión su papel en la defensa colectiva, pero se ha mantenido una tensión entre ambas organizaciones derivada de la continua apelación de la Unión a la necesidad de aumentar sus capacidades propias y su autonomía para defender intereses no compartidos. Durante mucho tiempo cualquier intento de potenciar la cooperación en seguridad y defensa en la UE era contemplado por algunos aliados -en particular el Reino Unido- como un intento de debilitar el papel de la Alianza Atlántica y, por extensión, la influencia de los Estados Unidos en la defensa Europea.

No se debe olvidar que tanto por el gasto en defensa como por las capacidades militares que los estados miembros pueden aportar a la organización, la OTAN depende esencialmente del compromiso de Estados Unidos, y eso se refleja también en el funcionamiento y la toma de decisiones en la Alianza.

Desde el final de la Guerra Fría la OTAN también ha ido redefiniendo sus funciones y objetivos, con el correspondiente impacto sobre la seguridad del Viejo Continente. Fundada

\footnotetext{
${ }^{39}$ Tardy, Thierry (2015), op. cit. pp. 17-20

${ }^{40}$ La Unión Europea, por su capacidad de combinar como actor internacional distintos instrumentos que van desde el ámbito del desarrollo hasta los de la seguridad y defensa, pasando por la diplomacia, el comercio, las finanzas o los derechos humanos, ha puesto en marcha lo que se conoce como "Comprehensive Approach" o aproximación multidimensional a las crisis y conflictos, combinando instrumentos de diversos tipos. Ver "The EU's Comprehensive Approach to External Conflict and Crises”, Join (2013) 30 final, Brussels, 11.12.2013, en www.eeas.europa.eu/statements/docs/2013/131211 03 en.pdf

${ }^{41}$ La información sobre estas misiones y operaciones está disponible en http://eeas.europa.eu/topics/militaryand-civilian-missions-and-operations_en

${ }^{42}$ Ver García González, Javier Ignacio: "Los Battlegroups de la Unión Europea: ¿Un instrumento eficaz para la gestión de crisis?, en de Cueto, Carlos y Calatrava, Adolfo (2012): Defensa y Globalización, Granada, Universidad de Granada-Mando de Adiestramiento y Doctrina, pp. 73-92. Ver también en este mismo volumen, Girona, Carlos: "Relanzando la respuesta rápida Militar: los Battlegroups", Revista UNISCI, n 42 (octubre 2016).
} 
tras la II Guerra Mundial para defender Europa y Norteamérica de las garras del comunismo, la desaparición de la Unión Soviética la dejó huérfana y desnortada durante un corto tiempo, abriendo incluso un debate sobre su supervivencia. A partir de mediados de los 90 reencontró una posición central con dos funciones principales: mediante la "proyección de estabilidad" sobre los países de Europa central y del este que llegaban a la democracia, y mediante la primera intervención militar de la OTAN “fuera de área”, en las guerras de los Balcanes. Allí la OTAN, y especialmente Estados Unidos dentro de ella, contribuyó con la gran mayoría de los medios militares que se emplearon de forma decisiva. La incapacidad de los países europeos para tratar por si mismos la conflictividad que afectaba directamente a su propia área de influencia, el mismo continente europeo, quedaba claramente de manifiesto por primera (y no última) vez. Gustara o no, el papel de la OTAN y particularmente de Estados Unidos fue insustituible.

El siguiente paso en la evolución de la Alianza llegaría como consecuencia de los ataques del 11 de septiembre de 2001. Por primera vez en su historia la OTAN activa el Art. 5 del Tratado de Washington y la organización asumió un papel importante en la intervención en Afganistán ${ }^{43}$. La defensa colectiva se ejercía así frente a amenazas globales; y la Alianza, con la participación también de los países europeos, allí estaba presente. La guerra de Afganistán será el principal asunto en la agenda de la OTAN durante muchos años, donde dirigiría la International Security Assitance Force (ISAF) desde 2003 a diciembre de 2014, llegando en su momento cumbre a desplegar más de 130.000 soldados $^{44}$. Desde enero de 2015 se mantiene en ese país la "Resolute Support Mission" (RSM), con tareas de entrenamiento, asesoramiento y asistencia, no de combate. En junio de 2016, el presidente Obama autorizó la expansión de estas tareas para incluir ataques aéreos y apoyos al Ejército afgano sobre el terreno.

Distinto fue el caso del otro gran escenario de conflicto abierto por Estados Unidos en los primeros años del siglo, la intervención en Iraq de 2003. En este teatro no se pondría en marcha una presencia de la OTAN -básicamente simbólica- hasta $2004^{45}$. Aquí las fuertes divisiones entre los países europeos, que respaldaban o rechazaban decididamente la política de la administración norteamericana de George W. Bush, ponían otra vez de manifiesto las dificultades para mostrar una "visión europea" o una unidad de acción sobre las cuestiones de seguridad y defensa. Por una parte, la cumbre de las Azores del 16 de marzo de 2003, donde los primeros ministros del Reino Unido, Portugal y España escenificaron el apoyo al Presidente Bush: por otra, la postura de Francia y Alemania en el Consejo de Seguridad, en contra de la acción contra Irak: es difícil encontrar una mejor representación posible de las divisiones. Las ampliaciones de la Alianza Atlántica -que había comenzado a incorporar a antiguos países del bloque soviético en 1999-, y la gran ampliación de la UE de 2004 no contribuyeron precisamente a esa "unidad de visión europea", al diversificarse aún más los intereses de seguridad de los miembros.

Si el papel de OTAN en la primera década del siglo XXI se recogía en el Concepto Estratégico aprobado en $1999^{46}$, en el que la influencia de las guerras de los Balcanes, y

\footnotetext{
${ }^{43}$ Gorka, Sebestyén: "Invocation in Context”, NATO Review, 2006.

${ }^{44}$ Ver NATO and Afghanistán, en www.nato.int/cps/en/natohq/topics 8189.htm

${ }^{45}$ Principalmente a través de una pequeña misión de entrenamiento que se extendió entre 2004 y 2011 . Ver NATO's asistance to Iraq (Archived) en www.nato.int/cps/en/natohq/topics 51978.htm

${ }^{46}$ Sobre la relación OTAN UE desde la perspeciva del Concepto Estratégico de la OTAN de 1999 ver Caracuel, María Angustias: "Una asociación estratégica genuina. La visión de la Unión Europea desde la OTAN", en VV. AA. (2012): Relaciones OTAN-Unión Europea a la vista del Nuevo Concepto Estratégico de la Alianza,

Documentos de Seguridad y Defensa 46, CESEDEN, pp. 41-44.
} 
Kosovo en particular, eran patentes, el Concepto Estratégico de la OTAN de $2010^{47}$ será el documento de referencia del nuevo tiempo.

Previamente a su aprobación, los Estados Unidos, por boca de su secretario de Defensa, Robert Gates, había manifestado su preocupación por la situación y actitudes en materia de defensa de los socios europeos. El 23 de febrero de 2010, en un discurso en la National Defense University sobre el Concepto Estratégico de la OTAN, tras enfatizar los problemas sistémicos que arrastraba la Alianza, entre ellos el tema presupuestario y de capacidades que los socios europeos debían resolver, manifestó los siguiente:

"These budget limitations relate to a larger cultural and political trend affecting the alliance. One of the triumphs of the last century was the pacification of Europe after ages of ruinous warfare. But, as I've said before, I believe we have reached an inflection point, where much of the continent has gone too far in the other direction. The demilitarization of Europe - where large swaths of the general public and political class are averse to military force and the risks that go with it has gone from a blessing in the 20th century to an impediment to achieving real security and lasting peace in the 21 st. Not only can real or perceived weakness be a temptation to miscalculation and aggression, but, on a more basic level, the resulting funding and capability shortfalls make it difficult to operate and fight together to confront shared threats". ${ }^{8}$

El juicio era certero. Los planteamientos postmodernos y kantianos que se habían consolidado en la UE en el mandato de Javier Solana, incluso con nombramientos sorprendentes como el de Robert Cooper, como "Director-General for External and PoliticoMilitary Affairs", un reconocido kantiano. A lo que se añadía algo que los Estados Unidos no querían reconocer: no favorecer una cierta autonomía europea en cuestiones de defensa conducía a que la OTAN se hubiese convertido en un refugio para la inacción y conformidad. En otras palabras, la OTAN actuaba de secante y contribuía a desactivar los compromisos de defensa de la mayoría de los Estados Miembros europeos.

De esta forma, el problema de fondo consistía en abordar esta cuestión, algo que no haría el nuevo el nuevo Concepto Estratégico.

Como señala su Prefacio "guiará la siguiente fase en la evolución de la OTAN, con el fin de que continúe siendo efectiva en un mundo cambiante, contra nuevas amenazas, con nuevas capacidades y nuevos socios". La reconfirmación de que sigue siendo el principal instrumento de defensa de los miembros (por lo tanto de Europa), incluso frente a nuevas amenazas, aparece inmediatamente en el texto. Justo después se recogerá el compromiso de la organización para "prevenir crisis, gestionar conflictos y estabilizar situaciones posconflicto", incluyendo aquí la cooperación y el trabajo más estrecho con los dos socios que considera más importantes, la Organización de Naciones Unidas (ONU) y la Unión Europea. Así pues, lo que en la UE estaría bajo el concepto de "gestión de crisis" aquí también se sigue incluyendo como parte fundamental de las funciones de la OTAN. Está abierto, por tanto, el espacio de colaboración con la Unión en todos estos tipos escenarios, pero a la vez también supone que la competencia en estos mismos ámbitos y teatros también es posible.

\footnotetext{
${ }^{47}$ Active Engagement, Modern Defence. Strategic Concept for the Defence and Security of the members of the North Atlantic Treaty Organization, NATO Summit in Lisbon, 19-20 November 2010, en http://www.nato.int/cps/en/natohq/topics_82705.htm

48 "Gates' Speech on the NATO Strategic Concept, February 2010", Council on Foreign Relations, en http://www.cfr.org/nato/gates-speech-nato-strategic-concept-february-2010/p21518.
} 
El Concepto Estratégico de 2010 reafirma rotundamente el vínculo transatlántico como parte de sus Tareas y Principios Fundamentales; la seguridad de los aliados de los dos lados del Atlántico es indivisible ${ }^{49}$. A partir de aquí, la relación con la Unión Europea tendrá una presencia destacable en el apartado que el Concepto Estratégico dedica a las asociaciones. Se reconoce la UE como una entidad con identidad propia, que como tal es un socio "único y esencial para la OTAN", reconociendo explícitamente "la importancia de una defensa europea más fuerte o más capaz", aunque no se señale en que se puede traducir esto.

El Concepto incluye un reconocimiento del Tratado de Lisboa como el nuevo marco de referencia para reforzar las capacidades de la Unión y se reafirma el papel complementario y de refuerzo mutuo que OTAN y UE juegan ${ }^{50}$, sin olvidar que este marco no debe dejar de lado a los aliados no miembros de la Unión. No hay mucha más concreción, aunque se incluyen cuatro puntos que no hacen sino incidir en el respeto da la autonomía del otro, en la complementariedad, en la voluntad de cooperar sobre el terreno, en las consultas políticas y en el desarrollo de capacidades "para minimizar duplicaciones y maximizar el costeeficacia",51, aunque esto ultimo siempre suena como restrictivo si se piensa en la posibilidad de que la UE desarrolle estructuras propias de mando o planeamiento.

Se trata por tanto de una formulación que permitía cierta profundización en las relaciones, pero también resultaba un tanto limitada y decepcionante si se comparaba con algunos trabajos preparatorios del Concepto Estratégico, como el informe del grupo de expertos dirigido por Madeleine Albright, que planteaba algunas recomendaciones de más calado que finalmente no se incluyeron ${ }^{52}$.

Directamente relacionado con el papel de la OTAN en su relación con la UE, será la evolución de la política de seguridad y defensa norteamericana en los últimos años, en particular los cambios producidos durante la administración del Presidente Obama. Si tradicionalmente Europa había sido centro de atención de la política exterior, de seguridad y defensa de Estados Unidos, los últimos años han dado muestras de un importante cambio de prioridades, con un giro estratégico hacia Asia, el conocido como "Pivote" asiático.

A finales del año 2011 y principios de 2012 la administración Obama ya anunciaba claramente que quería incrementar el papel de Estados Unidos en la región Asia-Pacífico ${ }^{53}$, tanto en los ámbitos de su política económica, política exterior y en su política de seguridad. En este último campo se concretó en la publicación del documento "Sustaining U.S. Global Leadership: Priorities for 21 st Century Defense" por parte del Departamento de Defensa ${ }^{54}$, en el que se señalaba sin ambages que "había que cambiar el equilibrio hacia la región AsiaPacífico" "55, y que la posición de Estados Unidos en Europa también se tenía que reequilibrar en una época de escasez de recursos (hacia una mayor responsabilidad de los aliados europeos, se entiende). En realidad el movimiento no era sorprendente, cuando el centro de gravedad de la actividad global se ha desplazado hacia esa zona, donde el peso de la economía china y su creciente participación e influencia en la política internacional es una realidad. E1 incremento de las capacidades militares de este país y las numerosas disputas territoriales en las que ha tomado un papel más activo, han servido de catalizador a ese movimiento.

\footnotetext{
${ }^{49}$ Active Engagement, Modern Defence. Strategic Concept... op. cit. punto 3.

${ }^{50}$ Ibid, punto 32 .

${ }^{51}$ Ibid.

${ }^{52}$ Caracuel, María Angustias, op. cit.

${ }^{53}$ Pivot to the Pacific? The Obama Administration's "Rebalancing” Toward Asia, Congressional Research Service, March 28, 2012. p. 1, en https://www.fas.org/sgp/crs/natsec/R42448.pdf

${ }^{54}$ Sustaining U.S. Global Leadership: Priorities for 21 st Century Defense, Department of Defense, USA, January 2012, en http://archive.defense.gov/news/Defense_Strategic_Guidance.pdf.

${ }^{55}$ Ibid, p. 2.
} 
El cambio en las prioridades estratégicas de los Estados Unidos levantó rápidamente todos los temores en el seno de los países europeos, acostumbrados a que los Estados Unidos les sacaran las castañas del fuego. Los 100.000 efectivos que Estados Unidos tenía desplegados en Europa en 2005 seguían reduciéndose, llegando a unos 62.000 en $2016^{56}$. El "desenganche" de Estados Unidos de la seguridad del Viejo Continente ya no era sólo una amenaza, sino que se estaba produciendo en la realidad. Pero no se estaba llevando a cabo porque los propios países europeos fueran capaces de asumir un mayor peso en su propia defensa y la participación norteamericana fuera menos necesaria, como algunos países llevaban décadas soñando. Se producía porque Estados Unidos identificaba sus principales intereses en otra región, y consideraba que Europa debía poder encargarse de los asuntos que principalmente les afectaban a ellos, en unos tiempos en los que la escasez de recursos era un problema importante para todos.

El tema económico no era un factor secundario. La OTAN siempre ha sido una organización donde el gasto en defensa de los miembros ha sido muy dispar, y la situación no se ha reequilibrado precisamente en la última década. Pocos son los países de la Alianza (también de la UE la mayor parte de ellos), que han cumplido con la directriz de dedicar al menos el 2\% del Producto Nacional Bruto (PNB) a defensa (solo Estados Unidos, Grecia y el Reino Unido en 2014; también Estonia y Polonia en 2015) ${ }^{57}$. El resto han mantenido porcentajes del PNB mucho menores, lo que directamente afecta a las capacidades que cada uno de estos países puede aportar a la defensa y la seguridad común.

La crisis económica comenzada en 2008, que ha afectado a todos los aliados de un lado y otro del Atlántico no ha hecho sino empeorar la situación. En el año 2009, Estados Unidos gastaba un 5,29\% de su PNB en defensa, mientras los aliados europeos de la OTAN en su conjunto solo dedicaban el 1,7\%, muy lejos del 2\% recomendado. En el año 2015, Estados Unidos había reducido su gasto al 3,59\% del PNB, pero los aliados europeos se habían alejado más aún del objetivo del $2 \%$, reduciendo el gasto en defensa al 1,45 del $\mathrm{PNB}^{58}$ como media.

En ese mismo año 2015, países como Alemania gastaban el 1.19\% del PNB, Francia el $1,80 \%$, Italia el 1,02\% y España -entre los más bajos- el 0,92\%. Aunque la posición, objetivos e intereses internacionales de estos países son claramente distintos que los de Estados Unidos (y por tanto sus requerimientos menores), la desproporción en el gasto resulta llamativa, más teniendo en cuenta que una parte de ese gasto norteamericano tiene directamente que ver con la seguridad Europea.

La guerra de Libia de 2011 fue el escenario donde este giro estratégico de los Estados Unidos y las consecuencias para la OTAN y para los países europeos se pusieron de manifiesto. Para empezar, la intervención militar, al amparo de la Resolución 1973 (2011) del Consejo de Seguridad de Naciones Unidas (CS), se produjo sin consenso entre los aliados europeos y con posturas muy diferentes en las discusiones que tuvieron lugar en el seno de la Unión sobre el tema libio. La imagen de Alemania -país central de la UE-, votando en el Consejo de Seguridad ${ }^{59}$ en distinto sentido que Francia y el Reino Unido, en una resolución que autorizaba el uso de la fuerza en la misma frontera sur de la Unión, ilustra perfectamente las dificultades para avanzar en una política de seguridad y defensa comunes. Diferencias de

\footnotetext{
${ }^{56}$ US Military Presence in Europe (1945-2016), U.S. European Command, 26 May 2016, en www.eucom.mil/doc/35220/u-s-forces-in-europe

${ }^{57}$ Defence Expenditures of NATO Countries (2009-2016), NATO, Press Release PR/CP (2016) 116, 4 July 2016 , en http://www.nato.int/nato_static_fl2014/assets/pdf/pdf_2016_07/20160704_160704-pr2016-116.pdf ${ }_{58}$ Ibid.

${ }^{59}$ Alemania se abstuvo en la votación, junto a Rusia, China, Brasil e India.
} 
intereses que también se han hecho visibles en los últimos años en otras situaciones como el conflicto en Siria o la respuesta a las acciones de Rusia en Crimea y Ucrania ${ }^{60}$.

Como señala Valasek, "La guerra de Libia nos da un probable esbozo de muchas futuras operaciones de la OTAN. Durante el conflicto, los Estados Unidos dejaron a sus aliados europeos el liderazgo de la operación, asumiendo un papel de apoyo y limitado por primera vez" ${ }^{\prime \prime}$. Para los norteamericanos, que no querían abrir un tercer frente en un país musulmán, lo que estaba sucediendo en Libia era un problema que interesaba fundamentalmente a los europeos y a ellos correspondía llevar el peso de la operación. La inviabilidad de una alternativa puramente europea para llevar a cabo la intervención, dejaba a la OTAN como el único instrumento factible, pero debería ser con una mínima participación de Estados Unidos, lo que se asumió por la administración Obama, aunque después de muchas dudas. Con la postura tomada en este conflicto, los Estados Unidos anunciaban que a partir de ese momento se iba a comportar como cualquier otro aliado: "no participar en algunas de las guerras de la OTAN y hacer solo lo necesario para ayudar a los demás a que las operaciones sean un éxito"62. La OTAN tenía que ser más europea, o seguramente no sería.

En este caso, fueron Francia y el Reino Unido quienes aportaron el principal esfuerzo, aunque durante las dos primeras semanas de la intervención el mando estratégico de la operación tuvo que ejercerlo Estados Unidos, pasando después a la OTAN. En cuanto a participación, sólo 10 de los 21 países de la Unión Europea miembros de la OTAN en ese momento se comprometieron a colaborar en la operación ${ }^{63}$, pero sólo cuatro de ellos se unieron a Francia y el Reino Unido en las misiones de ataque a tierra, la parte realmente comprometida de la operación. El resto ofrecieron capacidades que eran secundarias en este escenario, principalmente por condicionantes políticos ${ }^{64}$ y también de capacidades militares. Robert Gates lo volvió a describir acertadamente en un discurso en Bruselas, que por su interés citamos en algunos de sus párrafos:

"To be sure, at the outset, the NATO Libya mission did meet its initial military objectives - grounding Qaddafi's air force and degrading his ability to wage offensive war against his own citizens. And while the operation has exposed some shortcomings caused by underfunding, it has also shown the potential of NATO, with an operation where Europeans are taking the lead with American support. However, while every alliance member voted for Libya mission, less than half have participated at all, and fewer than a third have been willing to participate in the strike mission. Frankly, many of those allies sitting on the sidelines do so not because they do not want to participate, but simply because they can't. The military capabilities simply aren't there.

In particular, intelligence, surveillance, and reconnaissance assets are lacking that would allow more allies to be involved and make an impact. The most advanced fighter aircraft are little use if allies do not have the means to identify, process, and strike targets as part of an integrated campaign. To run the air campaign, the NATO air operations center in Italy required a major augmentation of targeting specialists, mainly from the U.S., to do the job - a "just

\footnotetext{
${ }^{60}$ Ver García González, Javier Ignacio: "Los conflictos armados, la defensa nacional y la Estrategia de Seguridad Nacional”, en Marquina, Antonio (ed.) (2015): La Estrategia de Seguridad Nacional 2013. Un pavimento deslizante, Madrid, UNISCI, pp. 280-283.

${ }^{61}$ Valasek, Tomas: "Introduction", en Valasek, Tomas (ed) (2012), All alone? What US retrenchement means for Europe and NATO, London, Centre for European Reform, pp. 1-2

${ }^{62}$ Ibid.

${ }^{63}$ War in Libya: Europe's confused response, IISS Strategic Comments, vol. 2011, $\mathrm{n}^{\mathrm{o}} 18$.

${ }^{64}$ Ibid.
} 
in time" infusion of personnel that may not always be available in future contingencies. We have the spectacle of an air operations center designed to handle more than 300 sorties a day struggling to launch about 150. Furthermore, the mightiest military alliance in history is only 11 weeks into an operation against a poorly armed regime in a sparsely populated country - yet many allies are beginning to run short of munitions, requiring the U.S., once more, to make up the difference.

In the past, I've worried openly about NATO turning into a two-tiered alliance: Between members who specialize in 'soft' humanitarian, development, peacekeeping, and talking tasks, and those conducting the "hard" combat missions. Between those willing and able to pay the price and bear the burdens of alliance commitments, and those who enjoy the benefits of NATO membership be they security guarantees or headquarters billets - but don't want to share the risks and the costs. This is no longer a hypothetical worry. We are there today. And it is unacceptable". 65

Una muestra más de a donde habían llegado los planteamientos de seguridad y defensa europeos y de las limitaciones de la cooperación defensiva entre los países europeos, incluso en el seno de la Alianza, y entre los socios europeos y los Estados Unidos. A partir de ahora, si Estados Unidos daba continuidad a la posición mantenida en Libia, "la OTAN será tan fuerte o tan débil como los europeos decidan hacerla" ${ }^{\natural 6}$.

El deterioro de las relaciones con Rusia en los últimos años, a partir de la anexión de Crimea y del conflicto en Ucrania principalmente, ha hecho que la OTAN vuelva a mirar hacia el adversario de la Guerra Fría con recelo, y que Estados Unidos probablemente modere y ralentice ese proceso de "desenganche". En todo caso, los cambios tan profundos del sistema internacional en los últimos años hacen que cualquier posible vuelta a una "Guerra Fría" sea muy distinta a la que se vivió en el siglo XX. El nivel de interconexión en todos los ámbitos que caracteriza la actual sociedad internacional global hace que la "política de poder" en la actualidad tenga que ser muy distinta de la de épocas precedentes.

\section{5.- La relación UE-OTAN y La Estrategia Global}

En el contexto y con los precedentes que hemos señalado en los apartados anteriores se llevará a cabo la redacción de la nueva Estrategia Global de la Unión Europea (EG) presentada en junio de 2016. Un documento oscurecido, como señalamos, por el terremoto del Brexit, pero cuyos planteamientos en el ámbito concreto de la seguridad y la defensa europea probablemente habrá que tener muy en cuenta.

La sacudida que supone la próxima salida del Reino Unido de la UE parece haber liberado a las fuerzas partidarias de avanzar en la cooperación europea en temas de defensa, que han lanzado iniciativas en este ámbito como muestra de la continuidad y vitalidad del proyecto Europeo. Hay que recordar que históricamente el Reino Unido ha dificultado (o directamente bloqueado) la mayor parte de los intentos por fortalecer y reforzar la cooperación en temas de defensa en Europa, generalmente con el argumento que estas iniciativas debilitaban la OTAN y el vínculo transatlántico.

\footnotetext{
65 “Transcript of Defense Secretary Gates's Speech on NATO's Future", 10 June 2011, en http://blogs.wsj.com/washwire/2011/06/10/transcript-of-defense-secretary-gatess-speech-on-natos-future/ ${ }^{66}$ Valasek, Tomas: "Introduction"... op. cit. p. 2.
} 
En consecuencia, la salida del Reino Unido de la Unión -con la que no se contaba al redactar la Estrategia-, sin duda ha de tener un impacto sobre la relación UE-OTAN, que aún está por determinar; por una parte la Unión pierde uno de sus principales activos en el campo de la defensa, con unas Fuerzas Armadas potentes, con capacidad expedicionaria y con un presupuesto de defensa que es de los pocos que supera el $2 \%$ del PNB; por otra, como hemos señalado, la Unión "se libra" del país que más frenos ponía al desarrollo de la defensa europea, que ahora se mantiene como aliado dentro de la OTAN, a la que siempre dio prioridad. Una situación que, según se articule, puede llevar a la Política Común de Seguridad y Defensa a una debilidad estructural y a la irrelevancia si los otros miembros de la Unión no aumentan el compromiso, o por el contrario, abrir las puertas a un desarrollo sin precedentes del componente de defensa de la Unión.

Igualmente, para la OTAN supone un desafío enorme. Dejando al lado por un momento el papel que para la Alianza quiera reservar la administración norteamericana que salga de las elecciones de 2016 (que tendrá presente el giro estratégico señalado más arriba y la posición que Rusia quiera o pueda mantener en el futuro), podemos encontrarnos con una OTAN con varias salidas; una OTAN en la que la UE esté más cohesionada en cuestiones de defensa y esto suponga un reequilibrio de esfuerzos y de la visión compartida, o, por el contrario una OTAN que mantenga el bajo nivel de compromiso que muchos países tienen y que supondría una Alianza debilitada tanto en su parte norteamericana como europea continental. Esto tampoco beneficiaría a un Reino Unido que ya solo contará con este foro para la cooperación en defensa y seguridad de toda Europa, de la que tampoco puede escapar, aunque algunos lo pretendan.

El desarrollo de la EG deberá tener esto en cuenta. El impacto del Brexit en el campo de la defensa europea será muy importante, pero se añade a toda una serie de transformaciones del sistema internacional que se vienen produciendo desde hace tiempo, vinculadas en gran medida al proceso de globalización en todos los ámbitos y a la creciente interconexión y empuje del globalismo. El informe presentado por la Alta Representante al Consejo Europeo de Junio de 2015:"The European Union in a changing global environment. A more connected, contested and complex World"67, pretendía reflejar estos cambios, cara a la discusión y redacción de la EG, que se presentaría un año más tarde. Se trataba de hacer una especie de "valoración estratégica" que la EG pudiera tomar como referencia.

Es importante comprobar cómo este informe plantea claramente el cambio del centro de gravedad de la economía internacional hacia la región Asia-Pacífico, así como los desafíos políticos en esa región -también en otras- y el ascenso de las nuevas potencias de esa zona y de potencias regionales en otras. Según señala el informe "el sistema mundial ya no es bipolar, unipolar o incluso multipolar: la propia noción de 'polaridad' está en cuestión" 68 . Y desde luego ya no es eurocéntrico. Ese cambio de foco estaba también en la base del cambio de prioridades de la política exterior y de seguridad norteamericana con el Presidente Obama.

El informe plantea en varias ocasiones la necesidad de reforzar las capacidades europeas de defensa, cuyas deficiencias repasa abiertamente ya en el resumen ejecutivo y se desarrollan después en el texto ${ }^{69}$, en lo que es un ejercicio de autocrítica digno de mención por

\footnotetext{
${ }^{67}$ The European Union in a changing global environment. A more connected, contested and complex World, Strategic assessment of HR/VP in preparation of the 2016 EU Global Strategy on Foreign and Security Policy of June 2015, en https://eeas.europa.eu/docs/strategic_review/eu-strategic-review_strategic_review_en.pdf. Sobre su elaboración, ver también Misiroli, Antonio: "Introduction”, en EU Institute for Security Studies (2016):

Strategy Matters. EU Key Documents 2015-2016, Paris, EUISS, en http://www.iss.europa.eu/publications/detail/article/strategy-matters-eu-key-documents-2015-2016/

${ }^{68}$ The European Union in a changing... op. cit. p. 10.

${ }^{69}$ Ibid., p. 3 y 17.
} 
lo poco habitual. "Aunque la UE no es una alianza militar, no puede hacer caso omiso de la D de su PCSD" ${ }^{, 70}$ se afirma. No se lo puede permitir, como también se reconoce en el texto.

Son varias los motivos que empujan hacia la necesidad de mejora de las capacidades de defensa. Primero se plantea porque el Tratado de Lisboa facilita mejores instrumentos para ese refuerzo y para integrar la defensa con otras facetas de la política exterior. Además porque le ayudaría a reforzar la asociación con otras organizaciones, como la ONU o la misma OTAN, fundamental para el vínculo transatlántico, que se sigue considerando fundamental. En esa línea, se explica cómo la UE y sus miembros tienen que asumir más responsabilidades y desarrollar más sus capacidades para ampliar la colaboración con OTAN: "como la OTAN se vuelve a centrar en la defensa territorial, la Política Común de Seguridad y Defensa (PCSD) puede trabajar con la OTAN para poner más el acento en la gestión de crisis y en las amenazas híbridas"

Finalmente, no menos importante, el informe también señala que se trata de una necesidad propia del actual contexto internacional y de los cambios que se han producido. En sus propias palabras, "el actual nivel de ambición y objetivo de capacidades no están adaptados al entorno estratégico cambiante, que incluye amenazas híbridas, desafíos de seguridad internos y externos interconectados, y la creciente necesidad de que los europeos asuman la responsabilidad de su propia seguridad"72. Un cambio de gran envergadura, que hasta ahora no se ha hecho, sería fundamental si se quiere reforzar el papel de la UE en el actual escenario global.

Con este trabajo previo y un importante proceso de consultas entre Estados Miembros, las instituciones de la Unión Europea, y las opiniones de expertos y centros de estudios $^{73}$, se redactó la nueva EG de la UE, presentada en junio de 2016, en el contexto que señalamos al comienzo. Con el título "Shared Vision, Common Action: A Stronger Europe" el documento pretende ser el punto de partida para la definición de una futura política exterior y de seguridad de la Unión, incluida su política de defensa. Una política que parta de la "visión compartida" europea que se proyecta en el texto, que lleve a la acción común que el título señala. Todo ello desde una perspectiva global, como señala la Alta Representante en el Prólogo, global no sólo en el sentido geográfico, sino también en el conjunto de instrumentos y diferentes políticas a las que la estrategia afecta. Una aproximación mucho más próxima al complejo escenario internacional en el que las organizaciones tienen que convivir.

La estrategia hace una revisión importante de las relaciones entre la Unión Europea y la OTAN, desde un planteamiento que resulta novedoso respecto de documentos anteriores: la ambición de autonomía estratégica para la Unión Europea que se recoge en la EG. Se tratará de una novedad respecto del informe de 2015, que no recogía ni una sola vez la palabra "autonomía". En texto de la Estrategia se mencionará hasta en 5 ocasiones la idea de autonomía estratégica, que también está presente en el resumen ejecutivo ( 2 veces), y la propia Alta Representante la recogerá en su prólogo marcando claramente las intenciones del texto: "La Estrategia nutre la ambición de autonomía estratégica para la Unión Europea". Está idea que, con los matices que veremos, se proyectará sobre todo lo que tiene que ver con el desarrollo de la defensa europea en el texto y en su relación con la OTAN.

\footnotetext{
${ }^{70}$ Ibid., p. 3.

${ }^{71}$ Ibid., p. 13.

${ }^{72}$ Ibid., p. 15.

${ }^{73}$ Ver a este respect, EU Institute for Security Studies (2016): Towards an EU Global Strategy. Consulting the experts, Paris, EUISS, en http://www.iss.europa.eu/publications/detail/article/towards-an-eu-global-strategyconsulting-the-experts/

74 Shared Vision, Common Action: A Stronger Europe. A Global Strategy for the European Union's Foreign and Security Policy, en https://eeas.europa.eu/top_stories/pdf/eugs_review_web.pdf
} 
La Estrategia sostiene de forma firme en el texto que los europeos, trabajando con sus socios, deben contar con las capacidades suficientes para defenderse por si mismos y cumplir con las expectativas derivadas de los compromisos de asistencia mutua y solidaridad de los tratados de los que forman parte ${ }^{75}$. No se pone en cuestión, por tanto, que la Unión se plantee prescindir de la colaboración con sus socios y aliados para la defensa colectiva, aunque de forma recurrente se reconoce la limitada aportación que hasta ahora los europeos han hecho al esfuerzo conjunto.

La Estrategia recoge como primera prioridad de su acción exterior la seguridad de la Unión $^{76}$, y lo plantea en términos tales como "tenemos que asumir una mayor responsabilidad para nuestra seguridad" o "aunque la OTAN existe para defender a sus miembros -la mayor parte de los cuales son europeos- de un ataque exterior, los europeos debemos estar mejor equipados, entrenados y organizados para contribuir decisivamente a tales esfuerzos colectivos, así como para actuar de forma autónoma cuando sea necesario"77. El reconocimiento implícito de que la contribución a ese esfuerzo colectivo no ha sido la más adecuada hasta ahora es claro, como lo es que los aliados deben mejorarlo (otra cosa es que lo hagan). La idea de autonomía estratégica aparecerá también en este apartado, no como un absoluto, sino en términos de "nivel apropiado" para mantener la seguridad.

Resulta novedoso también cómo ese nivel de ambición y de autonomía (siempre con la coletilla "en colaboración con otros") se plantea no sólo para la defensa colectiva o la respuesta a crisis externas (la gestión de crisis) sino también para responder a las nuevas amenazas en las que la distinción entre lo interno y lo externo es borrosa; el terrorismo, las amenazas híbridas, el ciberespacio, seguridad energética, crimen organizado y gestión de fronteras ${ }^{78}$. Todas estas son cuestiones fundamentales en el escenario de seguridad contemporáneo. En varios de estos ámbitos se propugna la colaboración con la OTAN, que ya ha visto su primer avance en la Declaración Conjunta que ambas organizaciones firmaron durante la Cumbre de Varsovia de la OTAN ${ }^{79}$.

La relación UE-OTAN se trata ampliamente en la Estrategia de forma explícita. No se cuestiona en absoluto que la OTAN sea el marco principal de cooperación en cuanto a la defensa colectiva para la mayor parte de los Estados Miembros de la Unión que también son de la OTAN (22 hasta que se concrete la salida del Reino Unido). Se afirma expresamente la voluntad de la UE de profundizar en la asociación con la OTAN, pero se afirma también muy claramente que la UE tiene que hacer un esfuerzo tanto para poder actuar de forma autónoma, llevar a cabo acciones en cooperación con la OTAN o contribuir mejor en su seno ${ }^{80}$. La defensa europea debe tener credibilidad, eficacia y capacidad de reacción.

La voluntad de autonomía y el refuerzo de la defensa europea que propugna la Estrategia son mucho más claros que en otras ocasiones, pero se plantean también como la mejor forma de reforzar el vínculo transatlántico y equilibrar el esfuerzo: "Una defensa europea más creíble es esencial también para mantener una asociación transatlántica saludable con Estados Unidos" $"$.

La Estrategia no es tan clara en cuanto a las estructuras de mando y planeamiento en las que debe apoyarse esa PCSD reforzada. Se habla de reforzar las estructuras de conducción

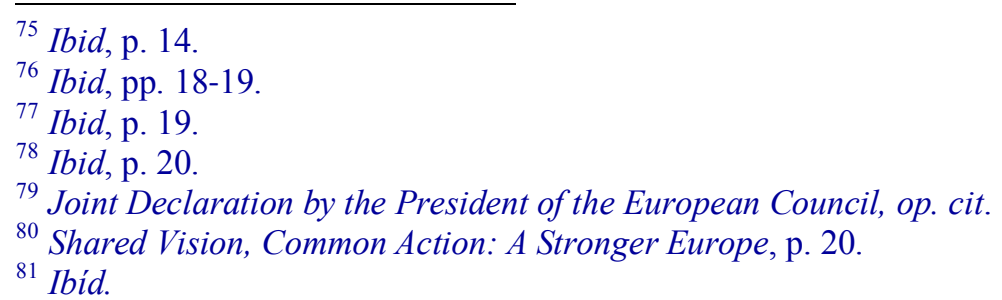


o planeamiento operacional, de una mayor cooperación de los Estados Miembros y de aprovechar de forma efectiva los instrumentos que el Tratado de Lisboa ofrece ${ }^{82}$, pero no se habla abiertamente de un eventual Cuartel General propio de la Unión Europea que unos siempre han visto como imprescindible para el desarrollo de la PCSD y de la "autonomía estratégica", y otros -encabezados por el Reino Unido- siempre han considerado como una duplicidad innecesaria con la OTAN, que desviaba recursos ya escasos y amenazaba la cohesión de la Alianza.

La Estrategia no obvia una cuestión absolutamente esencial de esa mejora de capacidades militares: la financiación y los aspectos presupuestarios. Que sean adecuados es una condición necesaria tanto para lograr esa autonomía estratégica como para tener una mejor contribución en la defensa colectiva a través de la OTAN. Sin ello todo lo demás son palabras vacías y mucho tienen que cambiar las cosas para revertir una situación en la que muy pocos miembros de la UE/OTAN alcanzan el 2\% del PNB del que siempre se habla como un mínimo.

La Estrategia plantea la necesidad de un gasto en defensa adecuado -que hasta ahora ha sido insuficiente- y hace un repaso por las capacidades militares críticas que son necesarias para los objetivos señalados, que se debe apoyar en una industria de defensa europea competitiva y sobre la base de la cooperación de los Estados Miembros. Debe hacerse de acuerdo y de forma coherente con el proceso de planeamiento de la OTAN. También en esta cuestión tiene en cuenta a la Alianza.

En definitiva, por lo que respecta a la relación entre la UE y la OTAN la EG opta por una vía clara: desarrollo fuerte de la PCSD, sin cuestionar a la OTAN en la defensa colectiva, intensificando la cooperación con ella, pero buscando un nivel de "autonomía estratégica" que hasta ahora no se había planteado nunca tan claramente, necesario para defender los intereses propios. Un refuerzo de la defensa europea que la EG ve imprescindible para respaldar el papel de la Unión en el nuevo contexto internacional (donde el poder blando no es suficiente), para defenderse de las nuevas amenazas y también para equilibrar el peso europeo en una OTAN sostenida fundamentalmente por los Estados Unidos. El concepto y la teoría están claros. ¿Tendrán los Estados Miembros la posibilidad y la voluntad de implementarla en la práctica?

\section{6.- Conclusión}

El Brexit parece que puede conseguir lo que casi 20 años de negociaciones en el proceso de desarrollo de la PESD/PCSD desde Saint-Malo no ha logrado: dar un impulso importante al proceso de integración europea en temas de seguridad y defensa.

La crisis existencial en la que el resultado del referéndum británico sumió a todo el proyecto de integración europeo ha sido respondido por los principales países del continente con Francia y Alemania a la cabeza-, con una apuesta importante: más integración, más Europa, y precisamente en el campo donde el Reino Unido siempre había puesto más obstáculos, la seguridad y la defensa. La EG de la Unión Europea proporciona el marco para hacerlo.

La Estrategia señala la "autonomía estratégica", pero sin cuestionar el papel principal de la OTAN en la defensa colectiva y hablando más de cooperación entre las organizaciones que no de competencia entra ellas (en el campo de la gestión de conflictos, que es donde podrían competir, no en otros ámbitos donde la UE no está preparada, como organización que

\footnotetext{
${ }^{82}$ Ibid, p. 47.
} 
no es militar). Así, la crisis que han generado los británicos, inicialmente un gran peligro, parece haberse convertido en una oportunidad, por lo menos en el campo de la defensa europea.

$\mathrm{O}$, tal vez, que no queda más remedio, como también se puede deducir de la $\mathrm{E} \mathrm{G}$; con el Reino Unido fuera de la UE, o se avanza por este camino de la mayor cooperación y compromiso, o Europa -la Unión Europea-, quedará permanentemente hundida en la irrelevancia y dependiendo de otros para su seguridad. Dependiendo de un aliado como Estados Unidos, con quien se mantiene una estrecha comunidad de valores e intereses en algunos ámbitos, pero con el que se compite en otros, dentro de un mundo cada vez más global y complejo. Porque Estados Unidos ya no tiene su centro de atención en Europa, aunque la Rusia actual le obligue a estar más presente de lo que querría. Sus prioridades ya están en otros escenarios y tiene sentido que se plantee por qué tiene que seguir siendo el proveedor de seguridad de una de las principales áreas económicas del mundo, que no quiere asumir su parte de la responsabilidad en la organización común, la Alianza Atlántica. Una OTAN que se ha mantenido de la mano de Estados Unidos, que todos siguen considerando esencial para la defensa colectiva de sus miembros, pero que se tendrá que reequilibrar de algún modo; como se decía más arriba, o será más europea, o, probablemente, no será.

La Unión Europea (a 27, sin el Reino Unido) ya ha comenzado el camino. La cumbre de Bratislava de finales de septiembre de 2016, como algún analista señalaba, es el principio de una nueva narrativa, un nuevo relato $^{83}$ de una Europa que se enfrenta a desafíos importantes (crisis migratoria, terrorismo, los efectos de la globalización y una Rusia amenazante, entre otros), y que ve en la cooperación en defensa un instrumento para consolidarse: "Europa necesita fortalecerse. En ninguna parte es eso más cierto en que nuestra política de Defensa" decía Jean-Claude Juncker en su discurso del "Estado de la Unión" el 14 de septiembre de $2016^{84}$.

La propuesta de revitalización de la PCSD presentada por Francia y Alemania, abogando por un plan de acción concreto a corto plazo que ponga en marcha lo recogido en la Estrategia va en ese sentido. Ambos países ya han puesto sobre la mesa una serie de puntos concretos en los se puede basar esta potenciación de la Unión, que se podría servir de la Cooperación Estructurada Permanente para desarrollarse. Hablamos por tanto de una propuesta abierta a todos los Estados Miembros, pero en la que si no todos ellos están dispuestos o preparados para participar, sería llevada adelante por aquellos que estén dispuestos a hacerlo. Esta parece que sería la vía que permita un desarrollo creíble de la defensa europea en el futuro próximo, fundada en aquellos países que tengan el compromiso y la voluntad política de participar en ella, evitando el bloqueo de los que no. Italia y España ya se han unido a la propuesta franco-alemana, y a través de una carta conjunta remitida el 11 de octubre a los socios de la $\mathrm{UE}^{85}$, los cuatro países hacen un llamamiento a ese refuerzo efectivo de la defensa de la Unión Europea.

Dotar a la Unión de una capacidad de planificación y de conducción de operaciones propias -un Cuartel General europeo- y tener verdaderamente fuerzas disponibles que la UE pueda activar (aunque sean tan limitadas como un Battlegroup o parte del Eurocuerpo), sin las restricciones políticas y financieras que las han hecho inoperantes hasta el momento, son probablemente los objetivos principales a corto/medio plazo más importantes, según se recoge en las propuestas.

\footnotetext{
${ }^{83}$ Dempsey, Judy: “Europe's New Narrative in Bratislava”, Strategic Europe, Carnegie Europe, 16 September 2016.

${ }^{84}$ The fog of politics, The Economist, 24 September 2016.

${ }^{85}$ Beesley, Arthur: Italy and Spain warm to EU defence co-operation, Finantial Times, October 12, 2016.
} 
Ni por entidad, ni por los recursos disponibles para ponerlos en marcha, estás propuestas pueden competir -ni quieren- con la OTAN, sus estructuras y el papel que tiene en la defensa del continente. Nadie habla, porque ciertamente sería una entelequia, a pesar del mantra británico, de hacer un "ejército europeo" que pudiera cuestionar a una Alianza Atlántica con la que se quiere (se tiene que) seguir cooperando, porque nadie más ofrece lo que ella puede dar. El desafío es que la OTAN no llegue a ser también irrelevante y que los aliados de ambos lados del Atlántico la sigan considerando útil y necesaria.

Sin embargo, las propuestas franco-alemanas (ahora de los cuatro grandes europeos), por su carácter simbólico y por sus implicaciones operativas (permitirían por fin una autonomía estratégica mínima), supondrían un paso considerable en ese reforzamiento de la autonomía europea que los documentos estratégicos han recogido con frecuencia, pero hasta ahora no ha podido cumplirse. Aunque de forma muy limitada, pero la Unión Europea estaría un poco mejor preparada para el complejo mundo en el que le toca vivir.

\section{Bibliografía Seleccionada}

Active Engagement, Modern Defence. Strategic Concept for the Defence and Security of the members of the North Atlantic Treaty Organization, NATO Summit in Lisbon, 19-20 November 2010, en http://www.nato.int/cps/en/natohq/topics 82705.htm

Aldecoa, Francisco: “Una política de defensa europea compatible con la Alianza Atlántica”, en VV. AA. (2015): UE-EEUU: Una relación indispensable para la paz y la estabilidad mundiales, Cuadernos de Estrategia, $\mathrm{n}^{\circ} .177$, IEES/USP-CEU.

Arteaga, Félix: “¿La Estrategia Global de la UE?... déjela ahí”, Blog Elcano, 29 de junio de 2016, en http://www.blog.rielcano.org/la-estrategia-global-de-la-ue-dejela-ahi/

Caracuel, María Angustias: "Una asociación estratégica genuina. La visión de la Unión Europea desde la OTAN", en VV. AA. (2012): Relaciones OTAN-Unión Europea a la vista del Nuevo Concepto Estratégico de la Alianza, Documentos de Seguridad y Defensa 46, CESEDEN.

Conclusiones de la Presidencia. Consejo Europeo de Bruselas, 14 de diciembre de 2007, 166616/07, en http://data.consilium.europa.eu/doc/document/ST-16616-2007-INIT/en/pdf

Consejo Europeo, 28 de junio de 2016, Conclusiones, Bruselas, EUCO 26/16.

Defence Expenditures of NATO Countries (2009-2016), NATO, Press Release PR/CP (2016) 116, 4 July 2016 , en http:/www.nato.int/nato_static fl2014/assets/pdf/pdf_2016 07/20160704 160704-pr2016-116.pdf

Dempsey, Judy: "NATO and the EU Agree to End Their Rivalry", Carnegie Europe, July 8, 2016, en http://carnegieeurope.eu/strategiceurope/?fa $=64045$

Dempsey, Judy: “Europe's New Narrative in Bratislava”, Strategic Europe, Carnegie Europe, 16 September 2016.

Duke, Simon: “The Future of EU- NATO Relations”, European Integration, Vol. 30, No 1, March 2008

European Council: The President, Report by President Donald Tusk to the European Parliament on the European Council of 28 June and the informal meeting of 27 EU Leaders on 29 June 2016, Statements and Remarks 412/16, 05/07/2016, en http://www.consilium.europa.eu/en/press/press-releases/2016/07/06-tuskreport-european-parliament/

European Union. External Action: About CSPD-The Berlin Plus Agreement, en http://eeas.europa.eu/csdp/aboutcsdp/berlin/

EU Institute for Security Studies (2016): Towards an EU Global Strategy. Consulting the experts, Paris, EUISS, en http://www.iss.europa.eu/publications/detail/article/towards-an-eu-global-strategy-consulting-the-experts/ 
Drent, Margriet (2015): "EU-NATO Relations in Crisis Management Operations: The Practice of Informality", en Freire, María Raquel y Galantino, María Grazia (2015): Managing Crisis, Making Peace. Towards a Strategic EU Vision for Security and Defense, Basingstok, Palgrave.

“Franco-German summit. Postdam, 1 December 1998”, en Rutten, Maartje (comp.) (2001): From St-Malo to Nice. European defence: core documents, Chaillot Papers 47, May 2001

Freire, María Raquel. y Galantino, María Grazia.: "Introduction: The Role of the EU in International Peace and Security”, en Freire, María Raquel y Galantino, María Grazia (2015): Managing Crisis, Making Peace. Towards a Strategic EU Vision for Security and Defense, Basingstok, Palgrave.

García González, Javier Ignacio: “Crisis y Gestión Militar de la Crisis en la Unión Europea: El Camino hasta la Actualización de la Estrategia Europea de Seguridad”, en UNISCI Discussion Papers, n 19 (2009), pp. 243-246.

García González, Javier Ignacio: "Los Battlegroups de la Unión Europea: ¿Un instrumento eficaz para la gestión de crisis?, en de Cueto, Carlos y Calatrava, Adolfo (2012): Defensa y Globalización, Granada, Universidad de Granada-Mando de Adiestramiento y Doctrina.

García González, Javier Ignacio: "Los conflictos armados, la defensa nacional y la Estrategia de Seguridad Nacional”, en Marquina, Antonio (ed.) (2015): La Estrategia de Seguridad Nacional 2013. Un pavimento deslizante, Madrid, UNISCI.

“Gates' Speech on the NATO Strategic Concept, February 2010”, Council on Foreign Relations, en http://www.cfr.org/nato/gates-speech-nato-strategic-concept-february-2010/p21518.

Gorka, Sebestyén: “Invocation in Context”, NATO Review, 2006.

Informe sobre la aplicación de la Estrategia Europea de Seguridad - Ofrecer seguridad en un mundo en evolución, Bruselas, 11 de diciembre de 2008, en http://www.consilium.europa.eu/uedocs/cms data/docs/pressdata/ES/reports/104637.pdf

Joint Declaration, British-French summit St-Mao, 3,4 December 1998, en http://www.consilium.europa.eu/uedocs/cmsupload/French-British\%20Summit\%20Declaration, \%20SaintMalo,\%201998\%20-\%20EN.pdf

Joint Declaration by the President of the European Council, the President of the European Commission, nd the Secretary General of the North Atlantic Treaty Organizations, Brussels, 8 July, 2016, en http://europa.eu/rapid/press-release_STATEMENT-16-2459 en.htm

Ministère de la Defense/ Presidence Français de la Union Européenne (2008): Objectives of the French Presidency of the European Union Council in terms of security and defense.

Missiroli, Antonio (ed.) (2015): Towards an EU Global Strategy. Background, process, references, EU Institute for Security Studies, Paris, 2015.

Misiroli, Antonio: "Introduction”, en EU Institute for Security Studies (2016): Strategy Matters. EU Key Documents 2015-2016, Paris, EUISS, en http://www.iss.europa.eu/publications/detail/article/strategy-matterseu-key-documents-2015-2016/

NATO and Afghanistán, en www.nato.int/cps/en/natohq/topics_8189.htm

NATO's asistance to Iraq (Archived) en www.nato.int/cps/en/natohq/topics_51978.htm

Pawlak, Patric: "A Global Strategy on foreign and security policy for the EU”, Briefing, European Parlamentary Research Service, EPRS, April 2016

Pivot to the Pacific? The Obama Administration's "Rebalancing” Toward Asia, Congressional Research Service, March 28, 2012, en https://www.fas.org/sgp/crs/natsec/R42448.pdf 
Presidence Français de la Union Européenne (2008): Un Europe qui agit pour repondre aux defis d'aujourd'hui ,Programme de Travail, 1er juillet-31 décembre 2008.

Shared Vision, Common Action: A Stronger Europe. A Global Strategy for the European Union's Foreign and Security Policy, en https://eeas.europa.eu/top stories/pdf/eugs review web.pdf

Solana, Javier (2004): "Prólogo", en Gnesotto, Nicole (ed.): Política de Defensa de la Unión Europea. Los cinco primeros años (1999-2004), París, Instituto de Estudios de Seguridad de la Unión Europea.

Sustaining U.S. Global Leadership: Priorities for 21st Century Defense, Department of Defense, USA, January 2012, en http://archive.defense.gov/news/Defense Strategic Guidance.pdf

Tardy, Thierry (2015): CSDP in Action-What Contribution to International Security, Chaillot Papers $\mathrm{n}^{\circ} 134$, ISSEU, May 2015

The Conventional Armed Forces in Europe (CFE) Treaty and Adapted CFE Treaty at a Glance, (August 2012), en www.armscontrol.org/factsheet/CFE

The European Union in a changing global environment. A more connected, contested and complex World, Strategic assessment of HR/VP in preparation of the 2016 EU Global Strategy on Foreign and Security Policy of June 2015, en https://eeas.europa.eu/docs/strategic review/eu-strategic-review strategic review en.pdf.

“The EU's Comprehensive Approach to External Conflict and Crises”, Join (2013) 30 final, Brussels, 11.12.2013, en www.eeas.europa.eu/statements/docs/2013/131211 03 en.pdf Towards a European Global Strategy. Securing European influence in a changing world, May 13, 2013, en http://www.realinstitutoelcano.org/wps/wcm/connect/4c2675804fc8b86b80b5caccba746acc/EGS Report.pdf?M $\underline{\mathrm{OD}=\mathrm{AJPERES} \& C A C H E I D=4 \mathrm{c} 2675804 \mathrm{fc} 8 \mathrm{~b} 86 \mathrm{~b} 80 \mathrm{~b} 5 \mathrm{caccba} 746 \mathrm{acc}}$

“Transcript of Defense Secretary Gates's Speech on NATO’s Future”, 10 June 2011, en http://blogs.wsj.com/washwire/2011/06/10/transcript-of-defense-secretary-gatess-speech-on-natos-future/ Una Europa segura en un mundo mejor - Estrategia Europea de Seguridad 2003, Bruselas 12 de diciembre de 2003.en https://www.consilium.europa.eu/uedocs/cmsUpload/031208ESSIIES.pdf,

US Military Presence in Europe (1945-2016), U.S. European Command, 26 May 2016, en www.eucom.mil/doc/35220/u-s-forces-in-europe

Valasek, Tomas: “Introduction", en Valasek, Tomas (ed) (2012), All alone? What US retrenchement means for Europe and NATO, London, Centre for European Reform.

War in Libya: Europe's confused response, IISS Strategic Comments, vol. 2011, nº 18. 